\title{
MODELING THE RELATIONSHIP BETWEEN THE POPULATION PREVALENCE OF PLASMODIUM FALCIPARUM MALARIA AND ANEMIA
}

\author{
ILONA A. CARNEIRO,* THOMAS SMITH, JOHN P. A. LUSINGU, ROBERT MALIMA, JÜRG UTZINGER, AND
} CHRIS J. DRAKELEY

Department of Infectious and Tropical Diseases, London School of Hygiene and Tropical Medicine, London, United Kingdom; Swiss Tropical Institute, Basel, Switzerland; National Institute for Medical Research, Amani Medical Research Centre, Amani, Tanzania; Centre for Medical Parasitology, University of Copenhagen, Copenhagen, Denmark; Joint Malaria Programme, Moshi, Tanzania

Abstract. More than half of all young children and pregnant women are affected by anemia. Although its etiology is multi-factorial, malaria is likely to be a major contributor to chronic anemia in endemic areas. Recent reviews have examined the effect of community-based malaria control interventions on anemia. We analyze how the prevalence of anemia depends on that of Plasmodium falciparum malaria by developing models of the excess risk of anemia caused by malaria at a population level in 24 villages in northeastern Tanzania. In that setting, we estimated that the prevalence of a hemoglobin level $<8 \mathrm{~g} / \mathrm{dL}$ attributable to malaria was $4.6 \%$ in infants, $4.1 \%$ in children one year of age, $2.7 \%$ in children two years of age, and $3.3 \%$ in women of childbearing age. Successful validation of our models in other malaria-endemic settings would enable their use for predicting the impact of malaria control interventions on anemia, and for long-term monitoring and surveillance of malaria.

\section{INTRODUCTION}

The etiology of anemia is usually multi-factorial. In the developing world, a host of factors play a role, most notably micronutrient deficiencies (especially iron deficiency), parasitic infections (particularly malaria and intestinal nematodes such as hookworms), infection with human immunodeficiency virus (HIV), chronic inflammatory disorders, and hemoglobinopathies. ${ }^{1-6}$ Recent literature reviews have established the causal relationship between malaria and anemia. Communitybased malaria control interventions, including antimalarial chemoprophylaxis, use of insecticide-treated nets (ITNs), and indoor residual spraying, consistently improved anemiarelated outcomes in young children. ${ }^{7,8}$ Therefore, Roll Back Malaria is considering the use of anemia as an additional indicator for measuring the impact of the introduction and/or scaling up of malaria control interventions. ${ }^{8}$ These include ITNs,, 10 routine intermittent presumptive treatment of infants $^{11}$ and a malaria vaccine ${ }^{12}$ distributed alongside the expanded program on immunization. However, there remain gaps in our knowledge about the association between malaria and anemia. Quantification of this association, and its relationship with age, would enable an enhanced understanding of the impact of malaria control interventions on the burden of anemia.

The purpose of this report is to examine how the prevalence of chronic anemia depends on that of Plasmodium falciparum malaria. Parasite and anemia prevalence data, measured in community-based surveys in northeastern Tanzania, ${ }^{13}$ were summarized by age group and village. We fitted a statistical model to predict the excess risk of anemia for each sub-group as a function of the prevalence of $P$. falciparum in that group. We consider the implications for estimates of the burden of chronic anemia attributable to $P$. falciparum malaria, and propose that our model, after successful validation in other settings, can be used for predicting the impact of malaria control interventions on anemia.

* Address correspondence to Ilona A. Carneiro, Department of Infectious and Tropical Diseases, London School of Hygiene and Tropical Medicine, Keppel Street, London WC1E 7HT, London, United Kingdom. E-mail: ilona.carneiro@lshtm.ac.uk

\section{MATERIALS AND METHODS}

Study area and population surveyed. Cross-sectional surveys were carried out in October-November 2001 and AprilJune 2002 in 24 villages representing 6 altitudinal transects across northeastern Tanzania. In children less than 15 years of age, the prevalence of stunting (height-for-age Z-score $<-2$ ) was $40.3 \%$ and the prevalence of wasting (weight-for-age Zscore $<-2$ ) was $6.8 \%$. The prevalence of alpha thalassemia ranged between $4 \%$ and $59 \%$, and the prevalence of sickle cell anemia ranged between $0 \%$ and $16 \%$. Both of these hemoglobinopathies appeared to be correlated with altitude and the prevalence of malaria (Drakeley CJ, unpublished data), and alpha thalassemia heterozygotes appeared to have lower hemoglobin $(\mathrm{Hb})$ levels (Enevold A, unpublished data). The prevalence of a deficiency in glucose-6-phosphate dehydrogenase was approximately $7 \% .{ }^{14}$ The prevalence of HIV is thought to be 6-7\% (Mbatia R, unpublished data). Details of the population surveyed and the field and laboratory techniques used have been presented elsewhere. ${ }^{13,15}$ Briefly, in each village an age-stratified sample of approximately 250 persons ( $<5$ years, 5-14 years, and 15-45 years of age) was recruited. Blood samples were collected from each individual and analyzed for the presence and density of malaria parasites using a standard, quality-controlled light microscopy technique. Hemoglobin levels were measured by standard hemophotometry (HemoCue, Ängleholm, Sweden).

Statistical methods. The parasitemia and anemia data were summarized within each survey and village by age-group, using one-year age groups up to four years and five-year age groups thereafter, leading to a total of 606 sub-groups. For the main analysis, we excluded the data of women 15-45 years of age, among whom anemia is specifically associated with menstruation and pregnancy, and carried out a separate analysis for these women. The prevalence of anemia, as a function of parasite prevalence, density, age group, and village, was analyzed using random effects logistic regression, with the full model of the form

$$
\operatorname{logit}\left(p_{A}(a, i, s)\right)=\beta_{a 0}+f\left(a, p_{p}(a, i, s)\right)+\beta_{s} I_{s}(s)+\gamma_{i},
$$

where $p_{A}(a, i, s)$ is the probability of being anemic in group with age-midpoint $a$, village $i$, and survey $s, p_{P}(a, i, s)$ is the 
corresponding parasite prevalence, $\beta_{a o}$ is the intercept, $\beta_{s}$ the regression coefficient for the survey effect where $I_{s}(s)$ is an indicator variable taking the value 0 for the first survey, and 1 for the second, and $\gamma_{i}$ is a random effect corresponding to village $i$. The observed number of anemic individuals, i.e., $r_{A}(a, i, s)$, of $n_{A}(a, i, s)$ individuals tested, was then assumed binomially distributed

$$
r_{A}(a, i, s) \sim \operatorname{Binomial}\left(n_{A}(a, i, s), p_{A}(a, i, s)\right)
$$

$r_{p}(a, i, s)$, the observed number of parasitemic individuals (of $n_{p}(a, i, s)$ tested) was also assumed binomially distributed, i.e.,

$$
r_{P}(a, i, s) \sim \operatorname{Binomial}\left(n_{P}(a, i, s), p_{P}(a, i, s)\right)
$$

Functions $f()$ of the forms:

$$
f\left(a, p_{P}(a, i, s)\right)=\beta_{a 1} \ln (a)+\frac{\beta_{P} p_{P}(a, i, s)}{p^{*}+p_{P}(a, i, s)}
$$

and

$$
f\left(a, p_{P}(a, i, s)\right)=\frac{\beta_{a 1} a^{*}}{a^{*}+a}+\frac{\beta_{P} p_{P}(a, i, s)}{p^{*}+p_{P}(a, i, s)}
$$

were evaluated, as were models including age-prevalence interaction terms. The use of sigmoidal functions on the logit scale enabled us to constrain the prevalence of anemia to vary monotonically with age and with parasite prevalence, while allowing for more possible shapes of curves than would a linear logistic model. The parameter $a^{*}$ corresponds to the age at which $50 \%$ of the maximal age effect is observed, and $\mathrm{p}^{*}$ to the parasite prevalence corresponding to $50 \%$ of the maximal parasitemia effect. In addition, models were assessed that included terms in the average parasite density for each sub-group.

The models were fitted using a Bayesian Markov chain Monte Carlo algorithm in the software package Winbugs version $1.4^{16}$ with the $\gamma_{i}$ assumed normally distributed (centered on 0 ), and appropriate imprecise priors were assigned for the other parameters. Model fit was assessed using the deviance information criterion (DIC), with lower DICs indicating improved fits. ${ }^{17}$

The full model contained all the terms we considered for inclusion. Because we required a model that could be applied to general situations, not just to the two surveys that we carried out, we also considered a model without terms in the survey (the reference model), i.e.,

$$
\operatorname{logit}\left(p_{A}(a, i, s)\right)=\beta_{a 0}+f\left(a, p_{P}(a, i, s)\right)+\gamma_{i}
$$

This was compared with simpler models from which additional terms were removed if they did not improve the fit.

The excess risk of anemia, $R_{A}(a, i, s)$, is estimated by the difference between the actual prediction and the prediction that would be made for the same age group, survey, and village at zero prevalence, i.e., in the case of the reference model

$$
R_{A}(a, i, s)=p_{A}(a, i, s)-\frac{1}{1+\exp \left(-\left(\beta_{a 0}+f(a, 0)+\gamma_{i}\right)\right)}
$$

We compute point and interval estimates for $R_{A}(a, i, s)$ by sampling from the posterior distribution implied by equation 7.

We carried out a separate analysis of anemia in women of childbearing age (i.e., 15-45 years) based on the assumption that pregnancy-associated anemia and malaria account for the higher prevalence in women than in men in this age group. Since there is little age-dependence in the anemia or parasitemia rates in adults, this analysis considered how the anemia prevalence in women of childbearing age compares with that in men, and how this is related to the overall parasite prevalence in the group defined at the level of survey within village. This was estimated using an additive model, i.e., we assume that

$$
r_{f}(i, s) \sim \operatorname{Binomial}\left(n_{f}(i, s), p_{f}(i, s)\right)
$$

where $r_{f}(i, s)$ is the number of anemic women among $n_{f}(i, s)$ sampled in village $i$, survey $s$ and

$$
p_{f}(i, s)=p_{m}(i, s)+\left(1-p_{m}(i, s)\right)\left(p_{f 0}+\left(1-p_{f 0}\right) \frac{\beta_{m} p_{P}(i, s)}{1+\beta_{m} p_{P}(i, s)}\right)
$$

where $p_{m}(i, s)$ is the corresponding prevalence in men; $p_{f o}$ is the excess risk of anemia in women in the absence of $P$. falciparum (we assume this is pregnancy-related, but not malaria-associated); $p_{p}(, i, s)$ is the overall prevalence of $P$. falciparum in adults in village $i$, survey $s$; and $\beta_{m}$ is then a coefficient quantifying the strength of the relationship between parasite prevalence and malaria attributable excess of anemia in women of childbearing age.

\section{RESULTS}

The overall prevalence of anemia ( $\mathrm{Hb}$ levels $<8 \mathrm{~g} / \mathrm{dL}$ and $<11 \mathrm{~g} / \mathrm{dL}$ ) was strongly related both to the age of the host and to the parasite prevalence (Figure 1). In both cases the anemia and parasite prevalence were slightly higher at the second survey during the long rain season than at the first survey during the dry season (Table 1$){ }^{13}$

Terms in age and parasite prevalence were both needed to give adequate predictions of the levels of anemia. The age effect on the prevalence of anemia could not be accounted for by the parasite prevalence alone, even when higher order terms in $p_{p}(a, i, s)$ were introduced into the model, nor could the prevalence effect be explained by age alone. Introducing a term for parasite density did not result in improved model fit, as measured by the DIC.

Testing of different forms of age dependence indicated that the main effect of age was best modeled with a sigmoidal function (equation 5). However, there was an interaction between the effect of age and parasitemia, with the best fit achieved by using a logarithmic transformation of age (equation 10). Models including interactions with sigmoidal functions of age were poorly identifiable and were therefore rejected in favor of the reference model (ii in Table 2) (equation 10).

$$
\begin{aligned}
\operatorname{logit}\left(p_{A}(a, i, s)\right)= & \beta_{0}+\frac{\beta_{a 1} a^{*}}{a^{*}+a}+\frac{\beta_{p} p_{P}(a, i, s)}{p^{*}+p_{P}(a, i, s)} \\
& +\beta_{1} p_{P}(a, i, s) \log (a)+\gamma_{i}
\end{aligned}
$$

The fit of the model was only improved slightly by including terms in the survey (compare models $\mathrm{i}$ and ii in Table 2), indicating that the between-survey variation in anemia was largely explained by the variation in parasite prevalence between survey periods. 

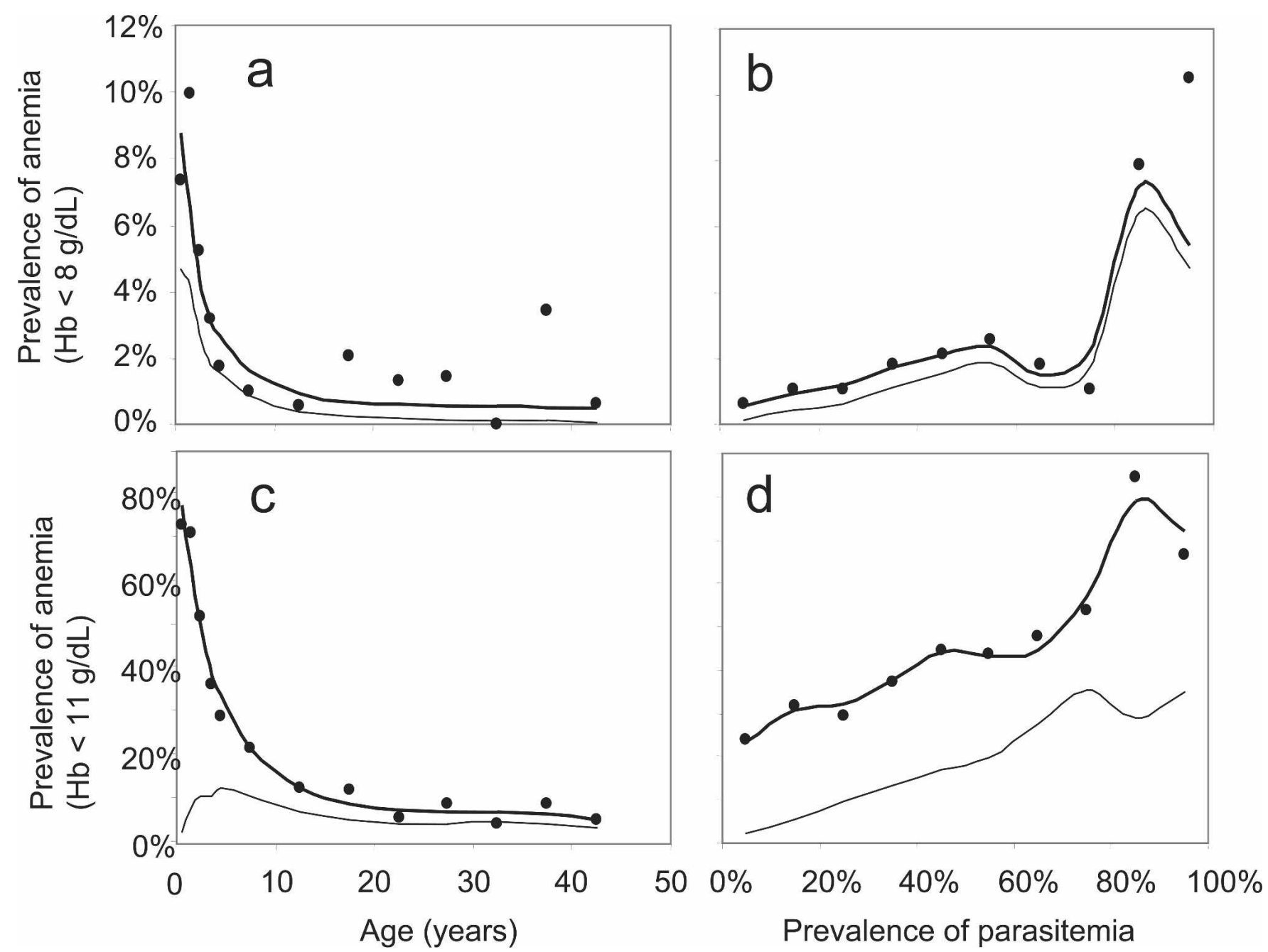

Figure 1. Prevalence and excess risk of hemoglobin (HB) levels $<8 \mathrm{~g} / \mathrm{dL}$ and $<11 \mathrm{~g} / \mathrm{dL}$. a, Prevalence and excess risk of an $\mathrm{Hb}$ level $<8 \mathrm{~g} / \mathrm{dL}$ by age. $\mathbf{b}$, Prevalence and excess risk of an $\mathrm{Hb}$ level $<8 \mathrm{~g} / \mathrm{dL}$ by Plasmodium falciparum prevalence. $\mathbf{c}$, Prevalence and excess risk of an Hb level $<11 \mathrm{~g} / \mathrm{dL}$ by age. d, Prevalence and excess risk of an $\mathrm{Hb}$ level $<11 \mathrm{~g} / \mathrm{dL}$ by $P$. falciparum prevalence. Points indicate the data (including adult women). The upper line shows the fitted prevalence from model ii equation 10 (excluding adult women) and the lower line shows the estimate of excess risk attributable to $P$. falciparum malaria.

We assumed the same relationships of anemia with age and parasite prevalence in all villages, but there was substantial variation between villages in anemia levels even after allowance for the differences in prevalence (compare models ii and iii in Table 2). The best fitting models therefore also included the random effect terms allowing for differences between vil-

TABLE 1

Unadjusted estimates of anemia and parasitemia*

\begin{tabular}{cccccc}
\hline & & & & & $\begin{array}{c}\text { Prevalence } \\
\text { of patent } \\
\text { Plasmodium } \\
\text { falciparum } \\
\text { parasitemia }\end{array}$ \\
\hline $\begin{array}{c}\text { Group } \\
\text { Children }\end{array}$ & 1 & 3,710 & $34.6 \%$ & $2.6 \%$ & $16.9 \%$ \\
$(0-14)$ & 2 & 3,627 & $35.0 \%$ & $3.7 \%$ & $23.5 \%$ \\
Men & 1 & 609 & $7.7 \%$ & $2.0 \%$ & $11.9 \%$ \\
$(15-45)$ & 2 & 589 & $9.7 \%$ & $1.4 \%$ & $14.8 \%$ \\
Women & 1 & 1,454 & $24.1 \%$ & $4.7 \%$ & $11.5 \%$ \\
$(15-45)$ & 2 & 1,443 & $25.8 \%$ & $3.6 \%$ & $17.3 \%$ \\
\hline$* \mathrm{Hb}=$ hemoglobin. & & & $\begin{array}{c}\text { Prevalence of } \\
\mathrm{Hb}<11 \mathrm{~g} / \mathrm{DL}\end{array}$ & $\begin{array}{c}\text { Prevalence of } \\
\mathrm{Hb}<8 \mathrm{~g} / \mathrm{dL}\end{array}$ \\
\end{tabular}

lages in anemia prevalence. For the model that we plan to generalize to other settings, we use estimates based on the reference model ii but without terms in the survey and with $\gamma_{i}=0$ (i.e., no village-level random effect). The parameter estimates for this model are given in Table 3.

We used model ii to estimate fitted values of the moderate anemia prevalence $(\mathrm{Hb}$ level $<8 \mathrm{~g} / \mathrm{dL}$ ) for each of the 606 sub-groups (Figure 1a and b). Although the age pattern of these predictions showed the expected decrease with age, the predicted anemia prevalence did not increase smoothly with parasite prevalence measured at the level of the group. This was because of the low number of villages with high parasite prevalence.

The fitted values of anemia prevalence (Hb levels $<8 \mathrm{~g} / \mathrm{dL}$ and $<11 \mathrm{~g} / \mathrm{dL}$ ) estimated for a hypothetical village with $\gamma_{i}=$ 0 showed the expected smooth patterns of decrease with age (Figure 2) and increase with parasitemia. A fraction of this anemia will be due to causes other than malaria. For this reason, we computed the excess risk associated with parasitemia by subtracting the estimated levels in the absence of 
TABLE 2

Comparisons of the fit of the model for prevalence of anemia

\begin{tabular}{|c|c|c|c|}
\hline & Model & Linear predictor & DIC* \\
\hline i & $\begin{array}{l}\text { Full model } \\
\quad(\text { equation } 1)\end{array}$ & $\begin{aligned} \beta_{0} & +\frac{\beta_{a 1} a^{*}}{a^{*}+a}+\frac{\beta_{P} p_{P}(a, i, s)}{p^{*}+p_{P}(a, i, s)} \\
& +\beta_{a 2} p_{P}(a, i, s) \ln (a)+\beta_{s} I_{s}(s)+\gamma_{i}\end{aligned}$ & \\
\hline ii & Reference model & $\begin{aligned} \beta_{0} & +\frac{\beta_{a 1} a^{*}}{a^{*}+a}+\frac{\beta_{P} p_{P}(a, i, s)}{p^{*}+p_{P}(a, i, s)} \\
& +\beta_{a 2} p_{P}(a, i, s) \ln (a)+\gamma_{i}\end{aligned}$ & 76 \\
\hline iii & $\begin{array}{l}\text { Reference model } \\
\text { without village } \\
\text { effect }\end{array}$ & $\begin{aligned} \beta_{0} & +\frac{\beta_{a 1} a^{*}}{a^{*}+a}+\frac{\beta_{P} p_{P}(a, i, s)}{p^{*}+p_{P}(a, i, s)} \\
& +\beta_{a 2} p_{P}(a, i, s) \ln (a)\end{aligned}$ & 79 \\
\hline iv & $\begin{array}{l}\text { Reference model } \\
\text { without age- } \\
\text { parasitemia } \\
\text { interaction }\end{array}$ & $\beta_{0}+\frac{\beta_{a 1} a^{*}}{a^{*}+a}+\frac{\beta_{P} p_{P}(a, i, s)}{p^{*}+p_{P}(a, i, s)}+\gamma_{i}$ & 77 \\
\hline V & $\begin{array}{l}\text { Reference model } \\
\text { with different } \\
\text { parameterization } \\
\text { of age effect }\end{array}$ & $\begin{aligned} \beta_{a 0} & +\frac{\beta_{P} p_{P}(a, i, s)}{p^{*}+p_{P}(a, i, s)} \\
& +\left(\beta_{a 1}+\beta_{a 2} p_{P}(a, i, s)\right) \ln (a)+\gamma_{i}\end{aligned}$ & 778 \\
\hline
\end{tabular}

* The figures given are for the fit of the model to the anemia prevalence data. A good fit is indicated by a low value of the deviance information criterion (DIC).

parasites from our estimates of anemia prevalence (Figure 3). The major impact of malaria on anemia in children has previously been shown to occur in children less than 2-3 years of age $^{8,18}$ and a similar age-related pattern was seen here. At the average levels of endemicity in the study area we estimated the prevalence of an $\mathrm{Hb}$ level $<8 \mathrm{~g} / \mathrm{dL}$ attributable to malaria to be $4.6 \%$ in the first year of life, $4.1 \%$ and $2.7 \%$ in children 1 and 2 years of age, respectively, which decreased to $0.8 \%$ in the 5-9-year-old age group and to approximately $0.1 \%$ in adult males.

We fitted an equivalent model to that of equation 10 to predict the prevalence of an $\mathrm{Hb}$ level $<11 \mathrm{~g} / \mathrm{dL}$. This showed an excellent fit to the age-prevalence relationship (Figure 1c) and to the relationship with prevalence of parasites (Figure 1d).

Unlike an $\mathrm{Hb}$ level $<8 \mathrm{~g} / \mathrm{dL}$, a level $<11 \mathrm{~g} / \mathrm{dL}$ is frequent even at very low levels of parasite prevalence. Thus, the proportion attributable to malaria is much lower than that for an Hb level $<8 \mathrm{~g} / \mathrm{dL}$. This is especially the case in the youngest children among whom the estimates of the excess risk of an
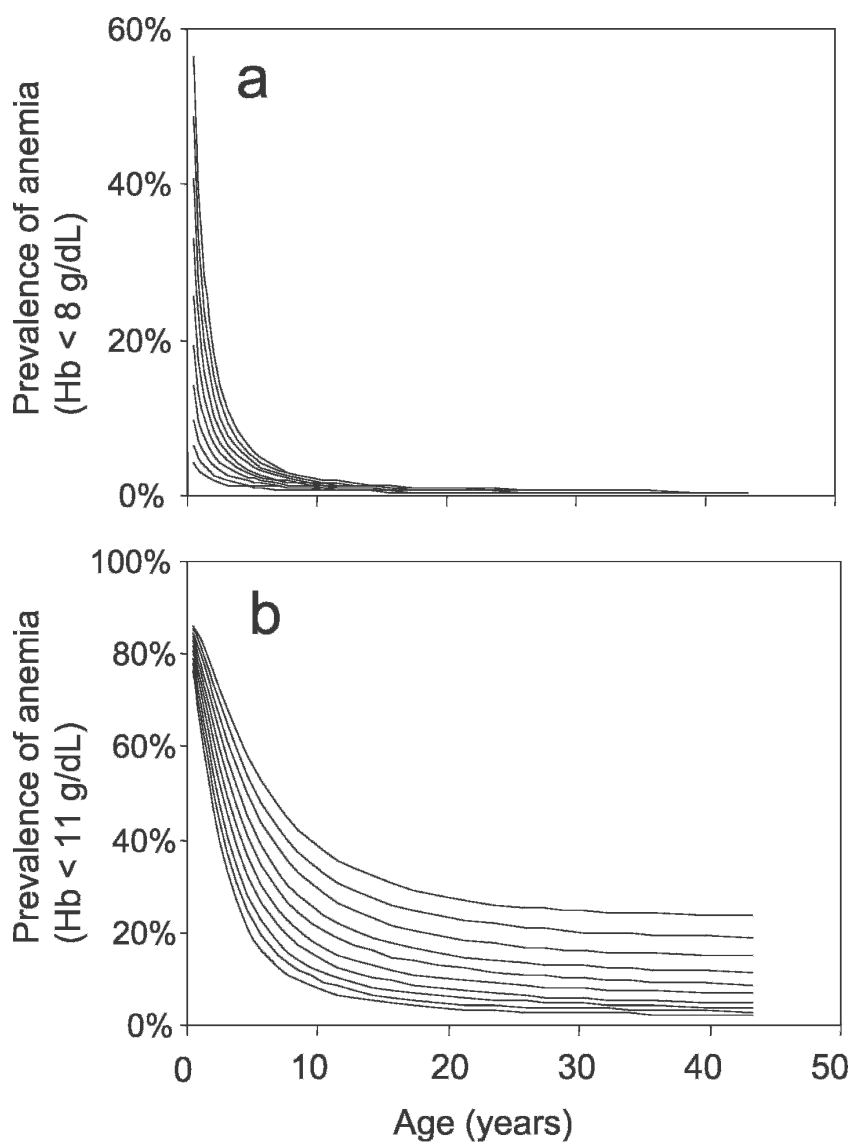

FigURE 2. Model predictions of the prevalence of hemoglobin $(\mathrm{Hb})$ levels $<8 \mathrm{~g} / \mathrm{dL}$ and $<11 \mathrm{~g} / \mathrm{dL}$. a, Prevalence of an $\mathrm{Hb}$ level $<8$ $\mathrm{g} / \mathrm{dL}$ by age. $\mathbf{b}$, Prevalence of an $\mathrm{Hb}$ level $<11 \mathrm{~g} / \mathrm{dL}$ by age. The predictions correspond to the fitted values from model ii equation 10 at $\gamma_{i}=0$. The lower lines correspond to the lowest parasite prevalence $(10 \%)$. The remaining lines correspond to predictions at $10 \%$ increments in parasitemia.

Hb level $<11 \mathrm{~g} / \mathrm{dL}$ did not increase monotonically with age at any given prevalence of parasitemia. This is because the estimated prevalence of an $\mathrm{Hb}$ level $<11 \mathrm{~g} / \mathrm{dL}$ in the absence of parasitemia is so high in the youngest children that there is little scope for an increase. The excess risk thus reaches a maximum in older children, when the baseline parasitemia has already decreased (Figure 3c).

The prevalence of $\mathrm{Hb}$ levels $<8 \mathrm{~g} / \mathrm{dL}$ and $<11 \mathrm{~g} / \mathrm{dL}$ in adult women (15-45 years of age) was much higher than in agematched men, and showed strong relationships with parasite

TABLE 3

Parameter estimates from the best-fitting model*

\begin{tabular}{|c|c|c|c|c|c|c|c|}
\hline & \multirow[b]{2}{*}{ Parameter description } & \multicolumn{3}{|c|}{ Estimates from model $\dagger$ for $\mathrm{Hb}<11 \mathrm{~g} / \mathrm{dL}$} & \multicolumn{3}{|c|}{ Estimates from model for $\mathrm{Hb}<8 \mathrm{~g} / \mathrm{dL}$} \\
\hline & & Mean & $2.5 \%$ & $97.5 \%$ & Mean & $2.5 \%$ & $97.5 \%$ \\
\hline$\beta_{0}$ & Intercept & -4.62 & -5.19 & -4.13 & -6.13 & -7.19 & -5.19 \\
\hline$\beta_{P}$ & Effect of parasite prevalence & 8.08 & 1.51 & 21.7 & 12.5 & 4.39 & 25.6 \\
\hline$p^{*}$ & Critical value of parasite prevalence & 6.52 & 3.74 & 25.0 & 2.84 & 0.59 & 7.03 \\
\hline$\beta_{a 1}$ & Magnitude of age effect (/year) & 6.36 & 5.86 & 6.91 & 3.14 & 1.92 & 4.42 \\
\hline$a^{*}$ & Critical age (years) & 4.70 & 3.81 & 5.69 & 3.66 & 1.75 & 6.51 \\
\hline$\beta_{1}$ & Age-prevalence inter-action effect & 0.50 & 0.13 & 0.90 & -0.75 & -1.52 & -0.04 \\
\hline
\end{tabular}




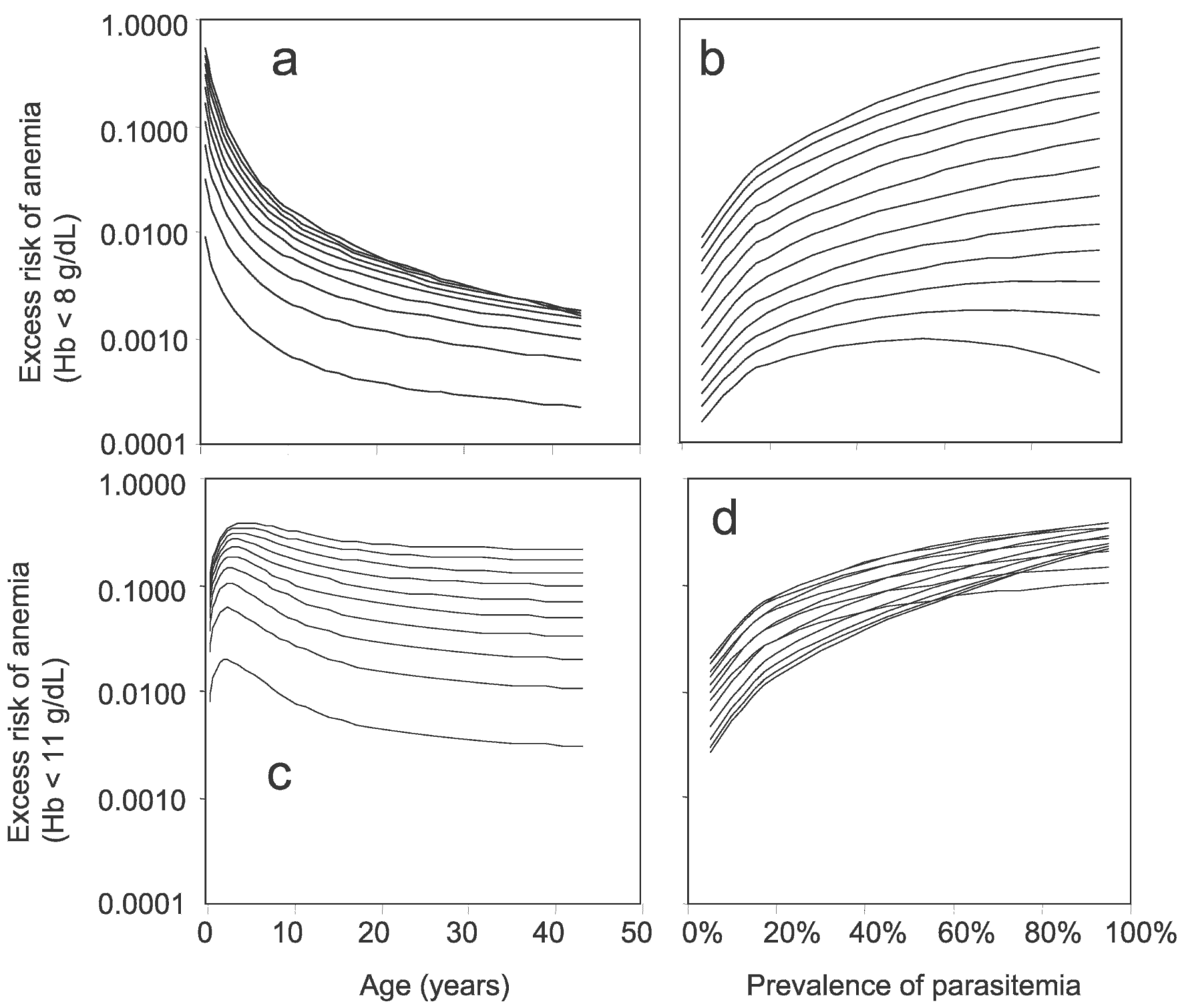

Figure 3. Model predictions of excess risk of hemoglobin $(\mathrm{Hb})$ levels $<8 \mathrm{~g} / \mathrm{dL}$ and $<11 \mathrm{~g} / \mathrm{dL}$. a, Excess risk of an $\mathrm{Hb}$ level $<8 \mathrm{~g} / \mathrm{dL}$ by age. b. Excess risk of an $\mathrm{Hb}$ level $<8 \mathrm{~g} / \mathrm{dL}$ by Plasmodium falciparum prevalence. c, Excess risk of an $\mathrm{Hb}$ level $<11 \mathrm{~g} / \mathrm{dL}$ by age. d, Excess risk of an $\mathrm{Hb}$ level $<11 \mathrm{~g} / \mathrm{dL}$ by $P$. falciparum prevalence. The predictions correspond to the fitted values from model ii equations 7 and 10 at $\gamma_{i}=0$. The lower lines in figures a and c correspond to the lowest parasite prevalence (10\%). The remaining lines correspond to predictions at $10 \%$ increments in parasitemia. The upper line in $\mathbf{b}$ corresponds to the midpoint of the youngest age group analyzed $(<1$ year of age) and the other lines in order to the age groups $1,2,3,4,5-9,10-14,15-19,20-24,25-29,30-34,35-39$, and 40-44 years of age at the last birthday. The lines are ranked in the same order at the left hand side of $\mathbf{d}$, but the lack of monotonicity in $\mathbf{c}$ results in lines crossing in the right hand part of figure $\mathbf{d}$.

prevalence (Figure 4). These relationships were captured by the additive binomial models (equation 9), which showed a good fit to both outcomes (Figure 5). The excess risk of an $\mathrm{Hb}$ level $<8 \mathrm{~g} / \mathrm{dL}$ in adult women compared with men in the absence of $P$. falciparum was estimated to be $1.3 \%$ and that of an $\mathrm{Hb}$ level $<11 \mathrm{~g} / \mathrm{dL}$ was estimated to be $6.1 \%$ (Table 4 ). Both of these percentages were estimated to strongly increase with parasite prevalence (Figure 5), so that at the average $P$. falciparum prevalence of $14.4 \%$ (Table 1 ), the difference in risk of an $\mathrm{Hb}$ level $<8 \mathrm{~g} / \mathrm{dL}$ between men and women is $3.3 \%$ and of an $\mathrm{Hb}$ level $<11 \mathrm{~g} / \mathrm{dL}$ is as high as $19.1 \%$. Although only women are susceptible to the effects of malaria infection during pregnancy, both pregnancy and menstruation impact anemia independently of any effects of malaria. At the average $P$. falciparum prevalence of $14.4 \%, 66 \%$ of the $\mathrm{Hb}$ levels
$<8 \mathrm{~g} / \mathrm{dL}$ in these women can be attributed to malaria exposure, which corresponds to a prevalence of malariaattributable anemia among women 15-45 years of age of $3.3 \%$.

\section{DISCUSSION}

The within-host dynamics of malaria anemia are complex, even in the non-immune host. ${ }^{19}$ Underlying reasons include malaria infection resulting in destruction of non-parasitized erythrocytes and diserythropoeisis, ${ }^{19,20}$ direct destruction of parasitized erythrocytes, ${ }^{21,22}$ and multiple genetic factors. ${ }^{3,4}$ Thus, anemia secondary to $P$. falciparum infection can result from a long series of events. The parasitologic status of the 

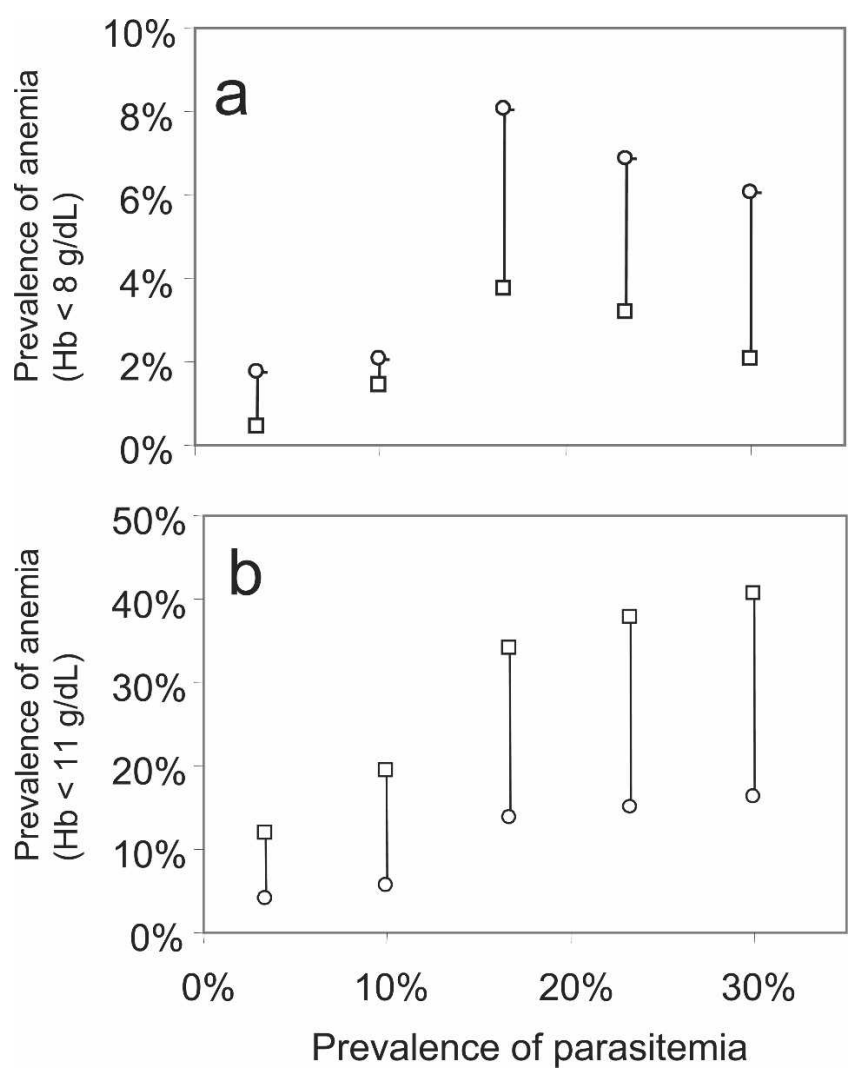

FIGURE 4. Prevalence of hemoglobin $(\mathrm{Hb})$ levels $<8 \mathrm{~g} / \mathrm{dL}$ and $<11 \mathrm{~g} / \mathrm{dL}$ in men and women. a, Observed prevalence of an $\mathrm{Hb}$ level $<8 \mathrm{~g} / \mathrm{dL}$. b. Observed prevalence of an $\mathrm{Hb}$ level $<11 \mathrm{~g} / \mathrm{dL}$ The upper points represent the data for women and the lower points represent data for men. The lengths of the vertical lines joining the points correspond to the risk difference.

host at the time of sampling may be a poor indicator of whether the anemia is mainly due to malaria, rather than nutritional deficiencies, concomitant infections, chronic inflammatory responses, or a combination of etiologic factors.

It is usually appropriate to assess epidemiologic exposures at the level of the individual. Assignment of group-level exposure measurements to individuals can lead to misclassification and to biased estimates of exposure-response relationships. However, the recent history of parasitization may be a better predictor of anemia than the level or presence of concurrent parasitemia. ${ }^{23}$ In a situation where infections are continually turning over in the population, the prevalence at village level represents a reasonable estimate of recent exposure of the individual, and this justifies the use of population level estimates of the burden of parasitism as one approach to predict malaria-associated anemia.

We were not able to predict the age distribution of anemia from either the parasite densities or parasite prevalence data alone. This indicates either age-dependence in other risk factors for anemia, or age-dependence in the vulnerability of the human host to the parasitologic insult as a result of acquired partial immunity, or a combination of these two factors. In malaria-endemic settings of sub-Saharan Africa, age patterns of anemia show a peak between 1 and 1.5 years. ${ }^{6}$ Importantly, the effect of malaria parasitemia on anemia has been shown to decrease with age. ${ }^{18}$ By including the age-parasitemia interaction term in our model, we hoped to capture this phe-
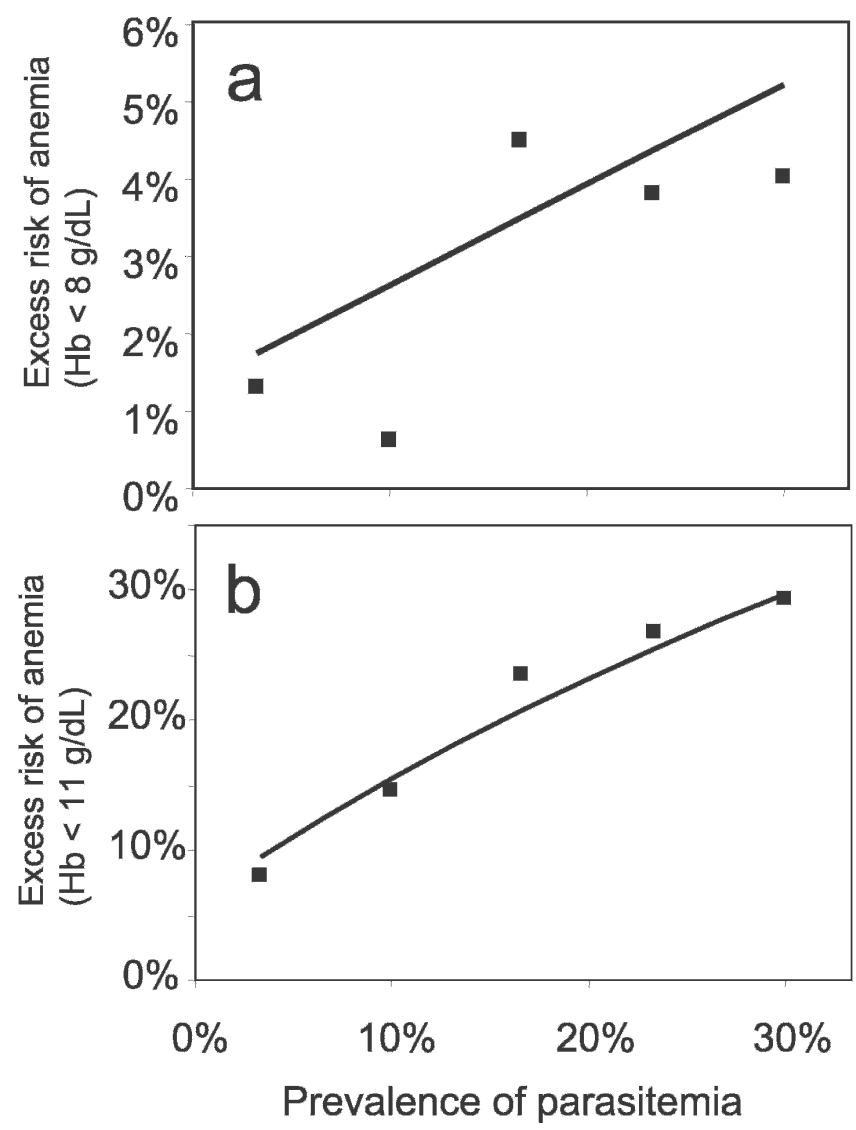

Figure 5. Excess risk of hemoglobin (HB) levels $<8 \mathrm{~g} / \mathrm{dL}$ and $<11 \mathrm{~g} / \mathrm{dL}$ in adult women. a, Excess risk of an $\mathrm{Hb}$ level $<8 \mathrm{~g} / \mathrm{dL}$. b, Excess risk of an $\mathrm{Hb}$ level $<11 \mathrm{~g} / \mathrm{dL}$. - = model predictions; $\mathbf{-}=$ observed risk difference.

nomenon. The dependence of our model on the logarithm of the age is potentially inconvenient if it is used to estimate anemia rates for very young babies, but we do not claim validity for the model in the youngest children, since the dynamics of $\mathrm{Hb}$ and erythropoiesis in the first few months of life are very different from those later in life.

Estimates of the global burden of $P$. falciparum malaria generally only include direct effects such as clinically relevant malaria fevers, cerebral malaria, severe malaria anemia, and death, with the latter accounting for the bulk of the burden. ${ }^{24-26}$ Inclusion of chronic anemia as an indirect effect of malaria infection is usually avoided because of the complexity of attributing the anemia to malaria. We have attempted to quantify the prevalence of malaria-related chronic anemia (Hb levels $<11 \mathrm{~g} / \mathrm{dL}$ and $<8 \mathrm{~g} / \mathrm{dL}$ ) by modeling the excess risk of anemia due to malaria at a population level.

TABLE 4

Parameter estimates from model for anemia in adult women (15-45 years of age)*

\begin{tabular}{llllllll}
\hline & \multicolumn{3}{c}{$\begin{array}{c}\text { Estimates from model } \\
\text { for } \mathrm{Hb}<11 \mathrm{~g} / \mathrm{dL}\end{array}$} & & \multicolumn{3}{c}{$\begin{array}{c}\text { Estimates from model } \\
\text { for } \mathrm{Hb}<8 \mathrm{~g} / \mathrm{dL}\end{array}$} \\
\cline { 2 - 3 } Parameter & Mean & $2.5 \%$ & $97.5 \%$ & & Mean & $2.5 \%$ & $97.5 \%$ \\
\hline$p_{f 0}$ & 0.061 & 0.04 & 0.083 & & 0.013 & 0.006 & 0.022 \\
$\beta_{m}$ & 1.12 & 0.86 & 1.38 & & 0.14 & 0.070 & 0.21 \\
\hline \multirow{2}{*}{$* \mathrm{Hb}=$ hemoglobin; $p_{f 0}=$ excess risk of anemia in women (compared to men) in the } \\
absence of Plasmodium falciparum; $\beta_{m}=$ increase in risk with prevalence of $P$. falciparum.
\end{tabular}


Our estimates suggest that in the epidemiologic setting of northeastern Tanzania where most villages surveyed were mesoendemic for malaria (i.e., parasite prevalence in children $0-4$ years of age $<50 \%$ ), more than $4 \%$ of children less than three years of age, and $3.3 \%$ of women of childbearing age, who bear the brunt of malaria disease, are affected by malaria-attributable $\mathrm{Hb}$ levels $<8 \mathrm{~g} / \mathrm{dL}$. The present analyses provide estimates of the prevalence of maternal anemia within the whole population of women of childbearing age without the need to consider what proportion of women are pregnant at any one time, or whether there are differences between primigravidae and multigravidae, although these differences have been documented. The contribution of malarial anemia during pregnancy is generally considered to be very important, resulting in impaired fetal development, premature delivery, low birth weight, maternal and infant anemia, and infant mortality. ${ }^{27,28}$

The study area was selected specifically to include a wide range of malaria transmission intensities, ${ }^{13,15}$ and therefore provides an average estimate of the proportion of anemia due to malaria in endemic areas. Further investigations in this area support the finding of a high excess risk of anemia due to malaria in very young children. ${ }^{29}$ The models presented here enable us to estimate the burden of malaria-related anemia at any given population prevalence, and can also be used to assess the potential impact on chronic anemia of different malaria intervention efforts. ${ }^{7,8}$

It is interesting to note that peak anemia prevalence seems to be closely linked to the age of admission for severe anemia in hospitals in the same study area. ${ }^{30}$ Although there is no clear link between moderate anemia and mortality, ${ }^{31}$ there is evidence that anemia can have substantial effects on cognitive and motor development and on growth. ${ }^{32,33}$ It has also been hypothesized that anemia may be associated with impaired immunity and consequently increased susceptibility to infectious disease. ${ }^{34}$ In this way, anemia, as an indirect effect of malaria may contribute to the malaria gap, i.e., the gap between the socioeconomic impact of the disease that can be documented in microeconomic studies, and the massive impact that is implied by macroeconomic studies using crosscountry regression analyses that compare malaria-free countries with those where the disease is highly endemic. ${ }^{35}$

It is therefore essential that estimates of malaria burden and evaluation of malaria interventions include the contribution of malaria to chronic anemia in the community. The models presented here enabled us to attribute a proportion of anemia to malaria in different age groups in northeastern Tanzania. Successful validation of the models in a range of settings across Africa, where the bulk of the malaria burden is currently concentrated, will allow prediction of the impact of different malaria interventions, including the introduction of malaria vaccines, under different transmission intensity scenarios.

Received September 18, 2005. Accepted for publication February 8, 2006.

Acknowledgments: This report is a product of the Joint Malaria Programme (JMP), a collaboration between the Tanzanian National Institute for Medical Research, Kilimanjaro Christian Medical School, the London School of Hygiene and Tropical Medicine, and the Centre for Medical Parasitology, University of Copenhagen, and the project "Mathematical modeling of the impact of malaria vaccines on the clinical epidemiology and natural history of Plasmodium falciparum malaria." We thank Amanda Ross for editorial support.

Financial support: The JMP was supported by the United Kingdom Medical Research Council and the Danish International Development Agency. Ilona A. Carniero is supported by the Department for International Development (United Kingdom). Chris J. Drakeley is supported by a Wellcome Trust Research Training Fellowship. The contributions of Thomas Smith and Jürg Utzinger were supported by the Program for Appropriate Technology in Health (PATH) Malaria Vaccine Initiative and GlaxoSmithKline Biologicals S.A.

Disclaimer: Publication of this report and the contents hereof do not necessarily reflect the endorsement, opinion, or viewpoints of the PATH Malaria Vaccine Initiative or GlaxoSmithKline Biologicals S.A.

Authors' addresses: Ilona A. Carneiro, Department of Infectious and Tropical Diseases, London School of Hygiene and Tropical Medicine, Keppel Street, London WC1E 7HT, London, United Kingdom, Telephone: 44-207-927-2686, Fax: 44-207-580-9075, E-mail: ilona .carneiro@lshtm.ac.uk. Thomas Smith and Jürg Utzinger, Swiss Tropical Institute, Socinstrasse 57, Postfach, CH-4002, Basel, Switzerland, Telephone: 41-61-284-8273, Fax: 41-61-284-8105, E-mails: Thomas-A.Smith@unibas.ch and juerg.utzinger@unibas.ch. John P. A. Lusingu and Robert Malima, National Institute for Medical Research, Amani Medical Research Centre, PO Box 4, Amani, Tanzania, Telephone: 255-27-264-0303, Fax: 255-27-264-3869, E-mails: jpalusingu@yahoo.co.uk and r_malima@hotmail.com. Chris J. Drakeley, Joint Malaria Programme, PO Box 2228, Moshi, Tanzania, Telephone: 255-27-275-3714, Fax: 255-27-275-3982, E-mail: chris .drakeley@1shtm.ac.uk.

Reprint requests: Ilona A. Carneiro, Department of Infectious and Tropical Diseases, London School of Hygiene and Tropical Medicine, Keppel Street, London WC1E 7HT, London, United Kingdom.

\section{REFERENCES}

1. Menendez C, Fleming AF, Alonso PL, 2000. Malaria-related anaemia. Parasitol Today 16: 469-476.

2. Nussenblatt V, Semba RD, 2002. Micronutrient malnutrition and the pathogenesis of malarial anemia. Acta Trop 82: 321-337.

3. Nagel RL, 2002. Malarial anemia. Hemoglobin 26: 329-343.

4. Ekvall H, 2003. Malaria and anemia. Curr Opin Hematol 10: 108-114.

5. Steketee RW, 2003. Pregnancy, nutrition and parasitic diseases. $J$ Nutr 133: 1661S-1667S.

6. Crawley J, 2004. Reducing the burden of anemia in infants and young children in malaria-endemic countries of Africa: from evidence to action. Am J Trop Med Hyg 71 (Suppl 2): 25-34.

7. Prinsen Geerligs PD, Brabin BJ, Eggelte TA, 2003. Analysis of the effects of malaria chemoprophylaxis in children on haematological responses, morbidity and mortality. Bull World Health Organ 81: 205-216.

8. Korenromp EL, Armstrong-Schellenberg JR, Williams BG, Nahlen BL, Snow RW, 2004. Impact of malaria control on childhood anaemia in Africa-a quantitative review. Trop Med Int Health 9: 1050-1065.

9. Curtis C, Maxwell C, Lemnge M, Kilama WL, Steketee RW, Hawley WA, Bergevin Y, Campbell CC, Sachs J, Teklehaimanot A, Ochola S, Guyatt H, Snow RW, 2003. Scaling-up coverage with insecticide-treated nets against malaria in Africa: who should pay? Lancet Infect Dis 3: 304-307.

10. Lengeler C, 2004. Insecticide-treated bed nets and curtains for preventing malaria. Cochrane Database Syst Rev: CD000363.

11. Schellenberg D, Menendez C, Kahigwa E, Aponte J, Vidal J, Tanner M, Mshinda H, Alonso PL, 2001. Intermittent treatment for malaria and anaemia control at time of routine vaccinations in Tanzanian infants: a randomised, placebocontrolled trial. Lancet 357: 1471-1477.

12. Alonso PL, Sacarlal J, Aponte J, Leach A, Macete E, Milman J, Mandomando I, Spiessens B, Guinovart C, Espasa M, Bassat Q, Aide P, Ofori-Anyinam O, Navia MM, Corachan S, Ceuppens M, Dubois MC, Demoitie MA, Dubovsky F, Menendez C, Tornieporth N, Ballou WR, Thompson R, Cohen J, 2004. 
Efficacy of the RTS,S/AS02A vaccine against Plasmodium falciparum infection and disease in young African children: randomised controlled trial. Lancet 364: 1411-1420.

13. Drakeley C, Carneiro I, Reyburn H, Malima R, Lusingu J, Cox J, Theander TG, Nkya WM, Lemnge MM, Riley E, 2005. Altitude dependent and altitude independent variations in Plasmodium falciparum prevalence in northeastern Tanzania. $J$ Infect Dis 191: 1589-1598.

14. Enevold A, Vestergard LS, Lusingu J, Drakeley CJ, Lemnge MM, Theander TG, Bygbjerg IC, Alifrangis M, 2005. Rapid screening for glucose-6-phosphate dehydrogenase deficiency and haemoglobin polymorphisms in Africa by a simple highthroughput SSOP-ELISA method. Malar J 4: 61.

15. Drakeley C, Corran P, Coleman P, Tongren J, McDonald SLR, Carneiro I, Malima R, Lusingu J, Manjurano A, Nkya W, Lemge M, Cox J, Reyburn H, Riley E, 2005. Estimating medium- and long-term trends in malaria transmission by using serological markers of malaria exposure. Proc Natl Acad Sci U $S$ A 102: 5108-5113.

16. Winbugs, 2003. Cambridge, United Kingdom: Medical Research Council Biostatistics Unit.

17. Spiegelhalter DJ, Best N, Carlin BP, van der Linde A, 2002. Bayesian measures of model complexity and fit (with discussion). J R Stat Soc B 64: 583-640.

18. Stoltzfus RJ, Chwaya HM, Montresor A, Albonico M, Savioli L, Tielsch JM, 2000. Malaria, hookworms and recent fever are related to anemia and iron status indicators in 0- to 5-y old Zanzibari children and these relationships change with age. $J$ Nutr 130: 1724-1733.

19. Jakeman GN, Saul A, Hogarth WL, Collins WE, 1999. Anaemia of acute malaria infections in non-immune patients primarily results from destruction of uninfected erythrocytes. Parasitology 119: 127-133.

20. Phillips RE, Looareesuwan S, Warrell DA, Lee SH, Karbwang J, Warrell MJ, White N, Swasdichai C, Weatherall DJ, 1986. The importance of anaemia in cerebral and uncomplicated falciparum malaria: role of complications, dyserythropoiesis and iron sequestration. QJM 58: 305-323.

21. Weidanz WP, Long CA, 1988. The role of T cells in immunity to malaria. Perlmann P, Wigzell H, eds. Progress in Allergy. Volume 41. Malaria Immunology. Basel: Karger, 215-252.

22. McDevitt M, Xie J, Gordeuk V, Bucala R, 2005. The anemia of malaria infection: role of inflammatory cytokines. Curr Hematol Rep 3: 97-106.

23. Kitua A, Smith TA, Alonso PL, Urassa H, Masanja H, Kimario J, Tanner M, 1997. The role of low level Plasmodium falciparum parasitaemia in anaemia among infants living in an area of intense and perennial transmission. Trop Med Int Health 2: 325-333.
24. Murphy SC, Breman JG, 2001. Gaps in the childhood malaria burden in Africa: cerebral malaria, neurological sequelae, anemia, respiratory distress, hypoglycaemia, and complications of pregnancy. Am J Trop Med Hyg 64: 57-67.

25. Snow R, Craig M, Newton C, Steketee RW, 2003. The Public Health Burden of Plasmodium falciparum Malaria in Africa: Deriving the Numbers. Bethesda, MD: Fogarty International Center, National Institutes of Health.

26. Carneiro IA, Roca-Feltrer A, Schellenberg JR, 2005. Estimates of the Burden of Malaria Morbidity in Africa in Children under the Age of Five Years. Geneva: World Health Organization. Child Health Epidemiology Reference Group Working Paper. Available at: http://www.who.int/child-adolescent-heath/New_ Publications/CHILD_HEALTH/EPI/CHERG_Malaria Morbidity.pdf.

27. Newman RD, Hailemariam A, Jimma D, Degifie A, Kebede D, Rietveld AE, Nahlen BL, Barnwell JW, Steketee RW, Parise ME, 2003. Burden of malaria during pregnancy in areas of stable and unstable transmission in Ethiopia during a nonepidemic year. J Infect Dis 187: 1765-1772.

28. Rogerson SJ, Pollina E, Getachew A, Tadesse E, Lema VM, Molyneux ME, 2003. Placental monocyte infiltrates in response to Plasmodium falciparum malaria infection and their association with adverse pregnancy outcomes. Am J Trop Med Hyg 68: 115-119.

29. Lusingu JP, Jones C, Akida J, Savaeli ZX, Kitua AY, Lemnge MM, Theander TG, 2004. Malaria morbidity and immunity among residents of villages with different Plasmodium falciparum transmission intensity in North-Eastern Tanzania. $\mathrm{Ma}$ lar J 3: 26.

30. Reyburn H, Mbatia R, Drakeley C, Bruce J, Carneiro I, Oloni R, Cox J, Nkya WM, Lemnge M, Greenwood BM, Riley EM, 2005. Association of transmission intensity and age with clinical manifestations and case-fatality of severe Plasmodium falciparum malaria. JAMA 293: 1461-1470.

31. Brabin BJ, Premji Z, Verhoeff F, 2001. An analysis of anemia and child mortality. J Nutr 131: 636S-645S.

32. World Health Organization, 2001. Iron Deficiency Anaemia: Assessment, Prevention and Control. A Guide for Programme Managers. Geneva, World Health Organization.

33. Grantham-McGregor S, Ani C, 2001. A review of studies on the effect of iron deficiency on cognitive development in children. J Nutr 131: 649S-666S.

34. Verhoef H, West CE, Veenemans J, Beguin Y, Kok FJ, 2002. Stunting may determine the severity of malaria-associated anemia in African children. Pediatrics 110: e48.

35. Malaney P, Spielman A, Sachs J, 2004. The malaria gap. Am J Trop Med Hyg 71 (Suppl 2): 141-146. 